\title{
Evaluation of Professional Self-esteem among EFL Teachers and Students at Mevlana University
}

\author{
Ebrahim KHEZERLOU*
}

\begin{abstract}
Self-esteem is generally defined as a global self-evaluation. It indicates the extent to which an individual believes the self to be capable, significant, successful and worthy (Rosse et al., 1991; Leary and McDonald, 2003). The study generally aims at measuring and correlating professional self-esteem perceptions of ELT professors $(\mathrm{N}=6)$ and prospective EFL teachers $(\mathrm{N}=79)$ at Mevlana University for diagnosing the pedagogical problems. Four professional self-esteem scales, each including 16 items, were developed to measure the participants' self-esteem perceptions in the five areas of (a) satisfaction, (b) knowledge development, (c) practice, (d) adaptation, and (e) communication. The average internal consistency reliability of the four scales was $r=0.86$. The findings revealed that there were statistically significant differences between the socio-demographic variables of Gender and Student-class and Student Self-report Self-esteem and between the socio-demographic variable of Student-class and Teacher Student-report Self-esteem. Moreover, they demonstrated slight positive correlation between Teacher Self-report Self-esteem and Teacher Student-report Self-esteem and moderate negative correlation between Student Self-report Self-esteem and Student Teacher-report Self-esteem. Finally, the regression findings showed that Student Self-report Self-esteem was better predicted by the Practice dimension, while Student Teacher-report Self-esteem by the development dimension.
\end{abstract}

Keywords: Evaluation, Professional Self-esteem, EFL Teachers, EFL Students

\footnotetext{
"English Department, Azarbaijan Shahid Madani University, Tabriz, Iran.
} 


\section{Introduction}

Self-esteem is generally defined as a global self-evaluation. It indicates the extent to which an individual believes the self to be capable, significant, successful and worthy. Psychologically, it is a state of mind that prepares the person to respond according to expectations of success, acceptance, and personal strength (Rosse et al., 1991; Bandura, 1997; Harter, 1999; Hoyle et al., 1999; Leary and McDonald, 2003). This is a global view of selfesteem of which domain-related self-esteems are derived, such as physical self-esteem (relating to physical appearance), academic self-esteem (concerning with academic achievements and skills), social self-esteem (pertaining to membership in a group), and professional self-esteem (describing the importance and value one attaches to one's profession). Professional self-esteem, the focus of the study, is often related to professional satisfaction, development, and adaptation (Aricak and Dilmac, 2003; Koc, 1994).

Whether self-esteem is assumed from a global or domain-related perspective, it is suggested that individuals with low self-esteem are emotionally more vulnerable and interact less adequately with others. Rosse et al. (1991) posit that individuals with low self-esteem tend to be less effective in interpersonal relationships and may have fewer resources to help them to cope with their problems. Furthermore, individuals with low self-esteem tend to be extremely dependent on others for validation, thus, making them particularly vulnerable in the emotionally charged environments. Perception of high self-esteem, on the other hand, has been associated with positive characteristics such as initiative, strong coping skills, feelings of confidence, feeling of worthiness, persistence in the face of challenges, feeling of positive regard about oneself, feeling of happiness, and longevity (Baumeister et al., 2003). People with high self-esteem feel good about themselves, feel a sense of belonging and security, and respect and appreciate others. They also tend to be successful in life because they feel confident in taking on challenges and risking failure to achieve what they want. Moreover, they have more energy for positive pursuits because their energy is not wasted on negative emotions, feelings of inferiority or working hard to please others at the expense of their own self-care (Leary and McDonald, 2003).

There also exists some evidence that self-esteem is significant in understanding pedagogical problems. For instance, Villa and Calvete (2001) in their study of self-esteem among secondary school teachers $(n=278)$ found that teachers with positive self-concept 
believed that they were able to influence student performance, while teachers with negative self-esteem were found to perceive dissatisfaction with their job. Moreover, Eggen and Kauchak (2004) observed a strong correlation between self-esteem and academic success.

Thus, the professional self-esteem is studied here to explore whether the evaluation of 'teacher self-esteem' and 'student self-esteem' among EFL teachers and students at Mevlana University are helpful in diagnosing their pedagogical problems, where most of the students are unmotivated and disengaged. Once again, it is logical to remind that self-esteem generally refers to the totality of a complex, organized, and dynamic system of learned beliefs, attitudes and opinions that each person holds to be true about his or her personal existence (Arthur, 1992). Evolving from this global self-esteem perspective, our professional self-esteem conceptualization includes five dimensions of (a) professional satisfaction (positive regards of teachers or students to teaching/learning and their work/course), (b) professional knowledge development (teachers and students' desire to develop necessary skills in their academic life), (c) professional practice (a sense of preparing for the work/course and performing a qualified work), (d) professional adaptation (feeling of adapting oneself to new work/course conditions to overcome challenges and problems), and (e) professional communication (teachers and students' desire to impart and share their knowledge, information, and experience to and with others). Hence, the paper aims at finding answers to the following research questions:

1. Are there significant differences between EFL students' self-esteem perceptions and their socio-demographic variables of (a) nationality, (b) gender, (c) student class, and (d) academic GPA?

2. Are there significant differences between EFL students' perceptions about the teacher self-esteem and their socio-demographic variables of (a) nationality, (b) gender, (c) student class, and (d) academic GPA?

3. What type of relationship is there between student self-report self-esteem and student teacher-report self-esteem?

4. What type of relationship is there between teacher self-report self-esteem and teacher student-report self-esteem?

5. According to students and their teachers, what are the strongest predictors of student self-esteem? 


\section{Methodology}

The participants were prospective EFL teachers $(\mathrm{N}=79)$ in their first, second, and third year of their study and ELT professors $(\mathrm{N}=6)$ at Mevlana University in Konya during 20122013 academic year. Four professional self-esteem scales, each including 16 items, were developed based on the literature study: Student Self-report Self-esteem Scale $(\alpha=.869)$, Teacher Student-report Self-esteem Scale $(\alpha=.941)$, Teacher Self-report Self-esteem Scale $(\alpha$ $=.682)$, and Student Teacher-report Self-esteem Scale $(\alpha=.954)$. They were used to measure the participants' perceptions in the five areas of (a) professional satisfaction, (b) professional knowledge development, (c) professional practice, (d) professional adaptation, and (e) professional communication. The collected data were entered into the SPSS version 17.0 for Windows for analysis. Descriptive and inferential statistics such as per cent, mean, t-test, ANOVA, correlation, and standard multiple regression were used for determining and explaining relationships between the variables.

\section{Results}

The results were offered based on the order of the research questions.

\subsection{Socio-demographic variables and student self-report self-esteem}

The results of T-test analyses showed that there was statistically a significant difference between Student Gender and Student Self-report Self-esteem $(t=-2.129 ; P=.036$, $P<.05)$. However, no significant difference was observed between Student Nationality and Student Self-report Self-esteem $(t=-.42 ; P=.674, P>.05)$ (See Table 1).

Table 1. Socio-demographic Variables and Student Self-report Self-esteem

\begin{tabular}{|c|c|c|c|c|c|c|c|c|c|c|c|}
\hline \multirow[b]{2}{*}{ Variables } & \multicolumn{3}{|c|}{ Group statistics } & \multicolumn{4}{|c|}{ t-test } & \multicolumn{4}{|c|}{ ANOVA } \\
\hline & & $\mathrm{N}$ & Mean & $\mathrm{t}$ & $\mathrm{df}$ & Sig. & $\eta^{2}$ & $\bar{F}$ & $\overline{\mathrm{df}}$ & Sig. & $\eta^{2}$ \\
\hline \multirow[t]{2}{*}{ Nationality } & Turkish & 75 & 77.02 & -.042 & 3.124 & .969 & - & - & - & - & - \\
\hline & Foreign & 4 & 77.50 & & & & & & & & \\
\hline \multirow[t]{2}{*}{ Gender } & Male & 29 & 72.65 & -2.129 & 77 & .036 & 0.055 & - & - & - & - \\
\hline & Female & 50 & 79.60 & & & & & & & & \\
\hline
\end{tabular}




\begin{tabular}{|c|c|c|c|c|c|c|c|c|c|c|c|}
\hline \multirow[t]{3}{*}{ Class } & First & 17 & 81.06 & \multirow{3}{*}{-} & \multirow{3}{*}{-} & \multirow{3}{*}{-} & \multirow{3}{*}{-} & \multirow{3}{*}{3.125} & \multirow{3}{*}{$2 ; 76$} & \multirow{3}{*}{.049} & \multirow{3}{*}{.076} \\
\hline & Second & 30 & 72.10 & & & & & & & & \\
\hline & Third & 32 & 79.56 & & & & & & & & \\
\hline \multirow[t]{5}{*}{ GPA } & $0-49$ & 3 & 75.33 & & & & & & & & \\
\hline & 50 to 59 & 21 & 74.67 & - & - & - & - & .741 & $4 ; 74$ & .567 & - \\
\hline & 60 to 69 & 13 & 80.38 & & & & & & & & \\
\hline & 70 to 84 & 27 & 75.22 & & & & & & & & \\
\hline & $85-100$ & 15 & 81.13 & & & & & & & & \\
\hline \multirow{3}{*}{$\begin{array}{c}\text { Post-hoc } \\
\text { Test }\end{array}$} & $1^{\mathrm{st}} \& 2^{\mathrm{nd}} *$ & & & & & & & - & - & .037 & - \\
\hline & $1^{\text {st }} \& 3^{\text {rd }}$ & - & - & - & - & - & - & - & - & .721 & - \\
\hline & $2^{\text {nd }} \& 3^{\text {rd } *}$ & & & & & & & - & - & .038 & - \\
\hline $\begin{array}{c}\text { Contrast } \\
\text { Tests }\end{array}$ & 2nd/1st \& 3rd & - & - & - & - & - & - & $(\mathrm{t}=-2.5)^{2}$ & $2 ; 76$ & .015 & - \\
\hline
\end{tabular}

Moreover, 'Effect Size' statistic based on the 'Eta Square' value $\left(\eta^{2}\right)$ of Cohen (1988) indicated a slight significant difference for male and female groups $\left(\eta^{2}=0.055 ; \eta^{2}<0.059\right)$. Cohen's (1988) effect size indexes for the ratio of variance between the dependent and independent variables, computed through the ' $\eta^{2}=\mathrm{t}^{2} / \mathrm{t}^{2}+\left(\mathrm{N}_{1}+\mathrm{N}_{2}-2\right)$ ' formula for t-tests, are as: small $=0.01$ to 0.059 , medium $=0.06$ to 0.139 and large $=0.14$ to 1 (See Table 1 ).

Furthermore, the results of One-way ANOVA analyses showed that there was statistically a significant difference between Student Class and Student Self-report Self-esteem $(F(2,76)=3.125, P=.049, P<.05)$, but no significant difference was observed between Student Self-report Self-esteem and Student Academic GPA $(F(4,74)=.741, P=.567, P>$ .05) (See Table 1). To determine which groups differed from each other, the LSD Post-hoc Test and Variance Contrast Tests were employed. The results revealed that there was statistically significant difference between second-class students on one hand and first- and third-class students on the other hand $(F(2,76)=.625, P=.015, P>.05)$ (See Table 1$)$.

At last, 'Effect Size' statistic based on the 'Eta Square' value $\left(\eta^{2}\right)$ for ANOVA revealed a moderate significant difference between the groups' self-esteem perceptions $\left(\eta^{2}=\right.$ $\left..076 ; \eta^{2}>.06<.139\right)$. 'Effect Size' for ANOVA is computed through the 'Eta Square $\left(\eta^{2}\right)=$ Sum of Squares of Between Groups/ Sum of Squares of Total' formula (here, the sum of 
squares of between groups was 1210.281, and the sum of squares of total was 15925.797) (See Table 1).

\subsection{Socio-demographic variables and teacher student-report self-esteem}

The results of T-test analyses showed that there were not statistically significant differences between Student Nationality and Teacher Student-report Self-esteem ( $t=-.306 ; P$ $=.761, P>0.05)$ and between Student Gender and Teacher Student-report Self-esteem $(t=-$ $.080 ; P=.937, P>0.05$ ) (See Table 2).

Table 2. Socio-demographic Variables and Teacher Student-report Self-esteem

\begin{tabular}{|c|c|c|c|c|c|c|c|c|c|c|c|}
\hline \multirow[b]{2}{*}{ Variables } & \multicolumn{3}{|c|}{ Group statistics } & \multicolumn{4}{|c|}{ t-test } & \multicolumn{4}{|c|}{ ANOVA } \\
\hline & & $\mathrm{N}$ & Mean & $\mathrm{t}$ & $\mathrm{df}$ & Sig. & $\eta^{2}$ & $\bar{F}$ & $\overline{d f}$ & Sig. & $\eta^{2}$ \\
\hline \multirow[t]{2}{*}{ Nationality } & Turkish & 75 & 73.28 & -.306 & 77 & .761 & - & - & - & - & - \\
\hline & Foreign & 4 & 76.25 & & & & & & & & \\
\hline \multirow[t]{2}{*}{ Gender } & Male & 29 & 73.21 & -.080 & 77 & .937 & - & - & - & - & - \\
\hline & Female & 50 & 73.56 & & & & & & & & \\
\hline \multirow[t]{3}{*}{ Class } & First & 17 & 82.77 & & & & & & & & \\
\hline & Second & 30 & 68.13 & - & - & - & - & 3.485 & $2 ; 76$ & .036 & .084 \\
\hline & Third & 32 & 73.44 & & & & & & & & \\
\hline \multirow[t]{5}{*}{ GPA } & $0-49$ & 3 & 66.33 & & & & & & & & \\
\hline & 50 to 59 & 21 & 72.71 & - & - & - & - & .250 & $4 ; 74$ & .909 & - \\
\hline & 60 to 69 & 13 & 76.54 & & & & & & & & \\
\hline & 70 to 84 & 27 & 72.30 & & & & & & & & \\
\hline & $85-100$ & 15 & 75.20 & & & & & & & & \\
\hline \multirow{3}{*}{$\begin{array}{c}\text { Post-hoc } \\
\text { Test }\end{array}$} & $1^{\text {st }} \& 2$ nd* & & & & & & & - & - & .010 & - \\
\hline & $1^{\text {st }} \& 3^{\text {rd }}$ & - & - & - & - & - & - & - & - & .093 & - \\
\hline & $2^{\text {nd }} \& 3^{\text {rd }}$ & & & & & & & - & - & .257 & - \\
\hline
\end{tabular}




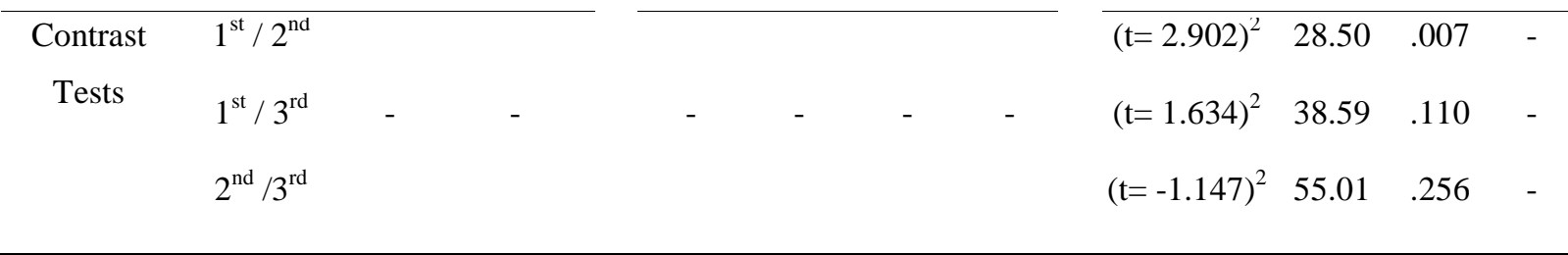

Moreover, the results of One-way ANOVA analyses showed that there was statistically a significant difference between Student Class and Teacher Student-report Selfesteem $(F(2,76)=3.485, P=.036, P<0.05)$, but no significant difference was observed between Student Academic GPA and Teacher Student-report Self-esteem $(F(4,74)=.250, P$ $=.909, P>0.05$ ) (See Table 2). To determine which groups differed from each other, the LSD Post-hoc Test and Variance Contrast Tests revealed that there was statistically significant difference between first-class and second-class students $(F(28.50)=8.42, P=.007, P<.05)$, not between first-class and third-class $(F(38.59)=2.67, P=.110, P>.05)$ and second-class and third-class students $(F(55.01)=1.32, P=.256, P>.05)$ (See Table 2).

Finally, 'Effect Size' statistic based on the 'Eta Square' value $\left(\eta^{2}\right)$ for ANOVA revealed a moderate significant difference between the first-class and second-class groups on their perceptions about teacher self-esteem $\left(\eta^{2}=.084 ; \eta^{2}>.06<.139\right)$. The sum of squares of between groups was 2322.967, and sum of squares of total was 27653.367 (See Table 2).

\subsection{Teacher-student self-esteem relationships}

The results of Pearson Correlation analyses showed that there was statistically a slight positive correlation between Teacher Self-report Self-esteem and Teacher Student-report Selfesteem ( $r=.295, N=6, P=.570 ; r>.10<.30$ ), while a moderate negative correlation was observed between Student Self-report Self-esteem and Student Teacher-report Self-esteem ( $r=$ -.359, $N=79, P=.251 ; \mathrm{r}>.30<.50)$ (See Table 3).

Table 3. Professional Self-esteem Correlations

\begin{tabular}{|c|c|c|c|c|c|c|}
\hline \multirow{3}{*}{ Relationships } & \multicolumn{4}{|c|}{ Group statistics } & \multicolumn{2}{|c|}{ Correlations } \\
\hline & $\mathrm{N}$ & Mean & Std. & Sig. & Teacher & Student \\
\hline & & \multicolumn{3}{|c|}{ Deviation } & Student-report & Teacher-report \\
\hline Teacher Self-report & 6 & 104.67 & 5.9554 & .570 & .295 & - \\
\hline
\end{tabular}




\begin{tabular}{ccccccc}
\hline Student Self-report & 79 & 77.05 & 14.2890 & .251 & - & -.359 \\
\hline Teacher Student-report & 79 & 73.43 & 18.829 & - & - & - \\
\hline Student Teacher-report & 12 & 70.75 & 21.1279 & - & - & - \\
\hline
\end{tabular}

\subsection{Student self-esteem prediction variances}

The results of multiple stepwise-method regression analyses for determining the prediction variance of each of the five dimensions of Student Self-report Self-esteem was as: Satisfaction $(t=1.159$; Beta $=.192)$, Knowledge Development $(t=1.526$; Beta $=.314)$, Practice $(t=1.527$; Beta $=.321)$, Adaptation $(t=1.549$; Beta $=.292)$, and Communication $(t$ $=1.350 ;$ Beta $=.207)($ See Table 4$)$.

Table 4. Predictors of Student Self-esteem

\begin{tabular}{|c|c|c|c|c|c|c|}
\hline \multirow[t]{2}{*}{ Dimensions } & \multicolumn{3}{|c|}{ Student Self-report } & \multicolumn{3}{|c|}{ Student Teacher-report } \\
\hline & Beta & $\mathrm{t}$ & Sig. & Beta & $\mathrm{t}$ & Sig. \\
\hline 1. Satisfaction & .192 & 1.159 & .000 & .341 & 3.615 & .006 \\
\hline 2. Development & .314 & 1.526 & .000 & .691 & 7.313 & .000 \\
\hline 3. Practice & .321 & 1.527 & .000 & .282 & 2.122 & .067 \\
\hline 4. Adaptation & .292 & 1.549 & .000 & .220 & 2.282 & .052 \\
\hline 5. Communication & .207 & 1.350 & .000 & .032 & .529 & .611 \\
\hline
\end{tabular}

Moreover, the results of multiple stepwise-method regression analyses for determining the prediction variance of each of the five dimensions of Student Teacher-report Self-esteem was as: Satisfaction $(t=3.615$; Beta $=.341)$, Knowledge Development $(t=7.313$; Beta $=$ $.691)$, Practice $(t=2.122$; Beta $=.282)$, Adaptation $(t=2.282$; Beta $=.220)$, and Communication $(t=.529$; Beta $=.032)$ (See Table 4$)$.

\section{Discussion}

The findings revealed that there were statistically significant differences between Student Self-report Self-esteem and Gender and Student-class variables. Indeed, the male and female groups with regard their self-esteem perceptions differed slightly from each other, where the mean score of females (Mean= 79.60) was greater than that of males $(M=72.65)$. 
This implies that females perceive more self-esteem in themselves than males. Moreover, there was moderate significant difference between second class (Mean= 72.10) students' selfesteem perceptions on one hand, and first class (Mean= 81.06) and third class (Mean= 79.56) ones' on the other hand, where the mean score of second class is less than that of the other two classes (See Table 1). This also means that the second class students perceive less selfesteem than first and third class students. Thus, research question one was answered.

With regard to the students' perceptions about the teacher self-esteem, the findings only demonstrated statistically significant difference between the socio-demographic variable of Student-class and Teacher Student-report Self-esteem. That is to say, the results showed moderate significant difference between the first- and second-class students' perceptions about the teacher self-esteem, not between first- and third-class and between second- and third-class students. The scrutiny of mean scores of first $($ Mean= 82.77) and second (Mean= 68.13) students showed that first-class students' mean score was greater than that of the second-class students (See Table 2). This implies that second-class students in comparison to first-class students perceive low self-esteem among their teachers. Thus, the second research question was answered. From the results of the question one and two, it can be concluded that students who perceive low self-esteem in themselves will attribute low self-esteem to their teachers, too.

Moreover, the findings with the correlations demonstrated slight positive correlation between Teacher Self-report Self-esteem (Mean=104.67) and Teacher Student-report Selfesteem $($ Mean= 73.43) (See Table 3). This implies that high level of self-esteem perceptions among teachers developed their students' perceptions about teacher self-esteem though it was not so great. From the results, it can also be inferred that teachers at Mevlana University has a homogeneous perception about their self-esteem because their standard deviation score (S.D. $=5.955$ ) is very low in comparison to their students' (S.D. = 18.829) (See Table 3). Accordingly, we have answered to our third research question.

Additionally, the correlation findings revealed moderate negative correlation between Student Self-report Self-esteem (Mean=77.05) and Student Teacher-report Self-esteem (Mean= 70.75) (See Table 3). This suggests that students perceive more self-esteem among themselves, while their teachers attribute low self-esteem to them at a moderate level. The standard deviation scores for Student Self-report Self-esteem (S.D. =14.289) and Student Teacher-report Self-esteem (S.D. = 21.128) also revealed that teachers at Mevlana University have not a homogeneous perception about student self-esteem because their standard deviation score was so greater than that of students, that is, some teachers have assigned very 
low and some others very high self-esteem scores to them (See Table 3). Thus, we have answered to our fourth research question.

Finally, the regression findings revealed that the Beta value of Practice dimension ( $t=$ 1.527; Beta $=.321)$ of Student Self-report Self-esteem and Development dimension $(t=7.313$; Beta $=.691)$ of the Student Teacher-report Self-esteem were greater than that of the other dimensions in their groups, that is, Student Self-report Self-esteem is better predicted by the Practice dimension, while Student Teacher-report Self-esteem by the development dimension. That is to say, from the point of view of students, the main reason in not sensing adequate self-esteem in themselves is that they do not practice what they have studied; whereas, from their teachers' point of view they do not want to develop their knowledge. Moreover, when Beta values were scrutinized for the other stronger predictive dimensions, the results showed Practice, Adaptation, Communication, and Satisfaction for students and Satisfaction, Practice, Adaptation, and Communication for their teachers, respectively (See Table 4). In short, to develop student self-esteem perception from the point of view of themselves, they should mainly prepare for their courses and perform a qualified work in their courses, while from the point of view of their teachers they should mainly increase their desire in acquiring necessary knowledge and skills for their courses. Accordingly, we have answered to our last research question.

\section{Conclusions}

Professional self-esteem describes the importance and value one attaches to one's profession. It was studied here to explore whether the evaluation of 'teacher self-esteem' and 'student self-esteem' among EFL teachers and students would shed light on their pedagogical problems. To this end, we conceptualized a professional self-esteem model aimed to measure the participants' perceptions in the five areas of (a) professional satisfaction, (b) professional knowledge development, (c) professional practice, (d) professional adaptation, and (e) professional communication. From the results, it was concluded that students who perceive low self-esteem in themselves will attribute low self-esteem to their teachers, too, and the increasing of teacher self-esteem perception will develop students' perceptions about teacher self-esteem. However, teachers can benefit from the results in diagnosing the parameters which affect their performance negatively and how to grow their awareness about factors leading them to increase their professional self-esteem. 


\section{References}

Aricak, T. \& Dilmac, B. (2003). An Investigation of Self-esteem and Vocational Self-esteem of Counseling Guidance Students. Trakya University Journal of Social Science, 3(1), 111-23. Arthur, D. (1992). Measuring the Professional Self-concept of Nurses: a Critical Review. Journal of Advanced Nursing, 17(6), 712-719.

Bandura, A. (1997). Self-esteem: the Exercise of Control. New York: Freeman.

Baumeister, R. F., Campbell, J. K., Krueger, J. I., \& Vohs, K. D. (2003). Does High Selfesteem Cause Better Performance, Interpersonal Success, Happiness, or Healthier Lifestyles? Psychological Science Public Interest, No: 4, 1-44.

Cohen, J. W. (1988). Statistical Power Analysis for the Behavioral Sciences (2nd Ed.). Hillsdale, NJ: Lawrence Erlbaum Associates.

Eggen, P. \& Kauchak, D. (2004). Educational Psychology: Windows on Classrooms (6th ed.). Pearson Education Inc, Upper Saddle River, New Jersey.

Harter, S. (1999). The Construction of the Self: A Developmental Perspective. New York: Guilford Press.

Hoyle, R., Kernis, M. H., Leary, M. R., \& Baldwin, M. W. (1999). Selfhood: Identity, Esteem, Control. Boulder, Westwood.

Koç, M. (1994). Factors Affecting Vocation Choices of Karadeniz Technical University Fatih Education Faculty first-year students. Modern Education Journal, 204, 27-30.

Leary, M. R. \& McDonald, G. (2003). Individual Differences in Self-esteem: a Review and Theoretical Integration. In M. R. Leary and P.J. Tangney (Eds.), Handbook of Self and Identity. New York: Guilford Press.

Rosse, G. J., Boss, W. R., Johnson, E. A., \& Crown, F. D, (1991). Conceptualizing the Role of Self-Esteem in the Burnout Process. Group Organization Management, Vol. 16, No: 4, 428-451.

Villa, A. \& Calvete, E. (2001). Development of the Teacher Self-concept Evaluation Scale and Its Relation to Burnout. Studies in Educational Evaluation. 27, 239-255. 